\title{
Expression of Xanthomonas campestris pv. vesicatoria Type III Effectors in Yeast Affects Cell Growth and Viability
}

\author{
Dor Salomon, Daniel Dar, Shivakumar Sreeramulu, and Guido Sessa \\ Department of Molecular Biology and Ecology of Plants, Tel-Aviv University, 69978 Tel-Aviv, Israel
}

Submitted 1 September 2010. Accepted 2 November 2010.

\begin{abstract}
The gram-negative bacterium Xanthomonas campestris pv. vesicatoria is the causal agent of spot disease in tomato and pepper. $X$. campestris pv. vesicatoria pathogenicity depends on a type III secretion system delivering effector proteins into the host cells. We hypothesized that some $X$. campestris pv. vesicatoria effectors target conserved eukaryotic cellular processes and examined phenotypes induced by their expression in yeast. Out of 21 effectors tested, 14 inhibited yeast growth in normal or stress conditions. Viability assay revealed that $X o p B$ and $X o p F 2$ attenuated cell proliferation, while AvrRxo1, XopX, and XopE1 were cytotoxic. Inspection of morphological features and DNA content of yeast cells indicated that cytotoxicity caused by XopX and AvrRxo1 was associated with cell-cycle arrest at G0/1. Interestingly, XopB, XopE1, XopF2, XopX, and AvrRxo1 that inhibited growth in yeast also caused phenotypes, such as chlorosis and cell death, when expressed in either host or nonhost plants. Finally, the ability of several effectors to cause phenotypes in yeast and plants was dependent on their putative catalytic residues or localization motifs. This study supports the use of yeast as a heterologous system for functional analysis of $X$. campestris pv. vesicatoria type III effectors, and sets the stage for identification of their eukaryotic molecular targets and modes of action.
\end{abstract}

The gram-negative bacterium Xanthomonas campestris pv. vesicatoria is the causal agent of spot disease in tomato and pepper plants (Jones et al. 1998). Like many other gram-negative bacterial pathogens of plants and animals, the ability of $X$. campestris pv. vesicatoria to promote disease largely depends on the type III secretion system (T3SS) (Buttner and Bonas 2006). This secretion apparatus translocates a suite of effector proteins directly into the cytosol of the host cell, where they act as virulence factors modulating cellular processes and suppressing host defense responses for the benefit of the pathogen (Block et al. 2008; Grant et al. 2006). In resistant plants, certain type III effectors may also act as avirulence (avr) factors where they are specifically recognized by corresponding resistance (R) proteins (Martin et al. 2003). This recognition event often results in the induction of the hypersensitive response (HR), a localized cell death of the infected tissues that ultimately arrests pathogen growth (Alfano and Collmer 2004). In recent years, a large group of type III effectors has been identified in $X$. campestris pv. vesicatoria strains by using various approaches

Corresponding author: G. Sessa; Telephone: +972.3.640.9766; Fax: +972.3.640.9380; E-mail: guidos@post.tau.ac.il

* The $\boldsymbol{e}$-Xtra logo stands for "electronic extra" and indicates that four supplementary figures and two supplementary tables are published online. based on avirulence activity, translocation into the host cell, co-regulation with the T3SS, and homology to known effectors (Gurlebeck et al. 2006; Roden et al. 2004b). The pool of known $X$. campestris pv. vesicatoria type III effectors includes approximately 30 proteins (Kay and Bonas 2009; White et al. 2009), most of them identified in strain 85-10, for which the complete genome sequence is available (Thieme et al. 2005).

A current challenge is to systematically determine the virulence functions, biochemical activities, and host targets of type III effectors of phytopathogenic bacteria. Understanding the functions of these proteins has been undermined by a combination of functional overlap or redundancy in the large effector repertoire of a given strain, the subtle effects that they may exert to increase virulence, roles that are possibly specific to certain stages of the pathogen life cycle, and detection of effectors by plant $\mathrm{R}$ proteins that trigger an HR cell death. Because of these constraints, molecular functions and host targets are known for only a limited number of $X$. campestris pv. vesicatoria effectors (Kay and Bonas 2009). Among them, AvrBs3, which is a member of a large family of transcription activatorlike (TAL) effectors from different phytopathogenic bacteria, acts as a transcription factor (Boch and Bonas 2010; Kay et al. 2007). The XopD effector protein has a modular structure and displays various biochemical activities (Kay and Bonas 2009). It contains a cysteine protease domain of the $\mathrm{C} 48$ family at the $\mathrm{C}$ terminus showing small ubiquitin-related modifier (SUMO) protease activity in vitro and in plants (Hotson et al. 2003). In addition, it contains an N-terminal domain for DNA binding and EAR motifs for repression of transcription (Kim et al. 2008). Indeed, XopD was shown to alter host transcription, promote pathogen growth, and delay development of disease symptoms (Kim et al. 2008). XopN suppresses basal defense responses and interacts with a tomato atypical receptor-like kinase and a group of 14-3-3 proteins that were proposed as its putative targets (Kim et al. 2009). XopX also suppresses basal defense responses (Metz et al. 2005), while XopJ inhibits host protein secretion and thereby interferes with cell-wall-associated defense responses (Bartetzko et al. 2009). The enzymatic activity of several $X$. campestris pv. vesicatoria effectors is postulated based on the presence of conserved catalytic domains in their protein sequences. For example, AvrRxv, AvrBsT, AvrXv4, and XopJ were proposed as putative cysteine proteases of the C55 family or as acetyltransferases (Gurlebeck et al. 2006), while XopE1 and XopE2 are putative transglutaminases (Thieme et al. 2007). Notably, AvrXv4 was shown to possess SUMO isopeptidase activity in plants (Roden et al. 2004a).

To circumvent limitations encountered in the investigation of effector functions in plant-pathogen systems and expedite discovery of $X$. campestris pv. vesicatoria effector targets and modes of action, we use the budding yeast Saccharomyces cerevisiae as a heterologous surrogate host. Yeast recently emerged 
as a model system for the identification and functional characterization of T3SS effector proteins (Curak et al. 2009; Siggers and Lesser 2008). The use of yeast in the study of pathogenic bacteria relies on the observation that effectors often target cellular processes that are conserved between yeast and other eukaryotes, such as those associated with vesicle trafficking, cytoskeleton dynamics, cell-cycle control, and programmed cell death (Valdivia 2004). Effectors that perturb conserved cellular processes often cause robust phenotypes when expressed in yeast, such as growth inhibition (Siggers and Lesser 2008). In contrast, expression of very few nontranslocated bacterial proteins affects yeast growth (Campodonico et al. 2005; Slagowski et al. 2008). In a large number of studies on effectors of bacterial pathogens of animals, growth-inhibition phenotypes were exploited to elucidate effector functions and targets (Curak et al. 2009; Siggers and Lesser 2008). Although yeast has not been used systematically to study the specific functions and targets of plant-associated effectors, several studies highlighted the great potential of using yeast in such analyses. Effectors of the tomato pathogen Pseudomonas syringae that suppress HR in plants were shown to suppress programmed cell-death in yeast (Abramovitch et al. 2003; Jamir et al. 2004). In addition, several $P$. syringae effectors were found to inhibit yeast growth (Munkvold et al. 2008). Significantly, the toxicity effect of three of them (HopAA1-1, HopAO1, and HopN1) well correlated with their virulence activity in plants (Espinosa et al. 2003; Lopez-Solanilla et al. 2004; Munkvold et al. 2008, 2009).

Here, we have expressed $21 \mathrm{X}$. campestris pv. vesicatoria type III effectors in yeast and found that the majority of them can inhibit yeast growth in normal or stress conditions. Among phenotypes induced by effectors in normal growth conditions, those caused by XopX and AvrRxo1 were associated with cell cycle arrest and cytotoxicity, whereas the phenotype induced by XopE1 was associated only with cytotoxicity. In addition, several $X$. campestris pv. vesicatoria effectors that caused deleterious effects in yeast also resulted in various degree of chlorosis or cell death when transiently expressed in $X$. campestris pv. vesicatoria host and nonhost plants. Moreover, toxicity in yeast caused by three $X$. campestris pv. vesicatoria effectors was dependent on amino acid residues required for their putative catalytic activity or cellular localization. Our study strongly supports the notion that a large number of $X$. campestris pv. vesicatoria type III effectors target cellular processes conserved in yeast and plants. In addition, it provides a wide repertoire of phenotypes induced by $X$. campestris pv. vesicatoria effectors in yeast that will be instrumental in elucidating their functions and roles in pathogenesis.

\section{RESULTS}

Seven $X$. campestris pv. vesicatoria type III effectors inhibit growth when expressed in yeast.

To uncover new biological functions of $X$. campestris pv. vesicatoria type III effectors, we performed a screen for effectors that inhibit growth when expressed in yeast. To this aim, genes encoding 21 type III effectors were first polymerase chain reaction (PCR) amplified from $X$. campestris pv. vesicatoria bacteria: 18 of them from the $X$. campestris pv. vesicatoria sp. strain 85-10 (Thieme et al. 2005), whereas three of them (AvrBs3, AvrBsT, and AvrXv4) from other X. campestris pv. vesicatoria strains. Effectors were then cloned in frame to a C-terminal myc tag in the centromere-containing shuttle vector pGML10. Following plasmid transformations into the yeast strain BY4741, effectors were expressed under the control of the galactose-inducible promoter GAL1 and protein accumulation was confirmed by Western blot analysis for all of them except XopE1 (Supplementary Fig. S1), which was previously reported to accumulate at low levels in leaves (Thieme et al. 2007). To identify $X$. campestris pv. vesicatoria effectors that perturb cellular functions and cause inhibition of yeast growth, yeast cultures were serially diluted and plated onto repressing (2\% glucose) and inducing ( $2 \%$ galactose and $1 \%$ raffinose) media. All yeast strains exhibited similar growth on repressing medium compared with a control strain containing an empty vector (Fig. 1). However, of the 21 X. campestris pv. vesicatoria effectors tested, expression of seven resulted in a distinct
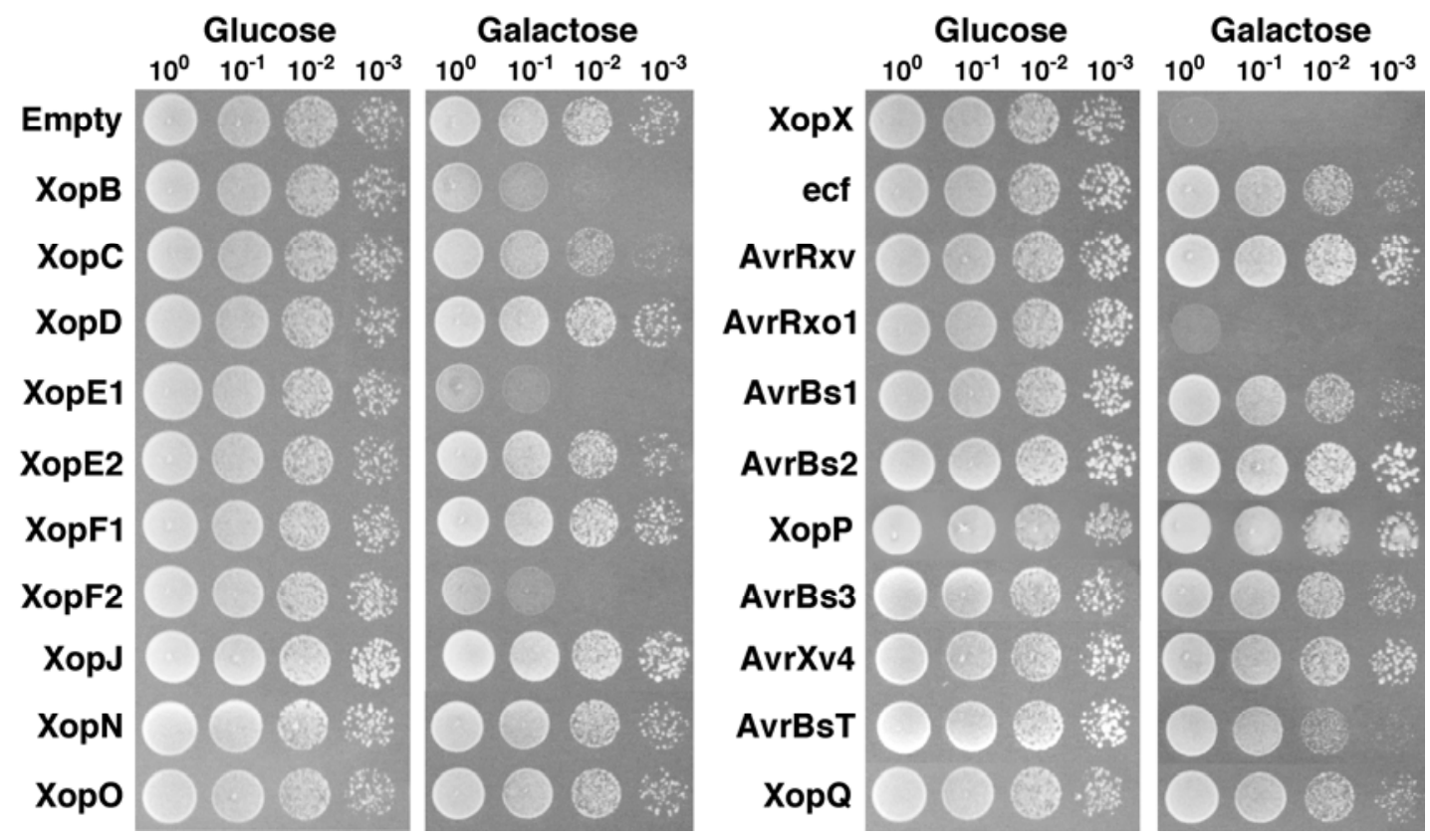

Fig. 1. Yeast growth is inhibited by expression of seven Xanthomonas campestris pv. vesicatoria type III effectors. BY4741 yeast strains carrying the lowcopy-number plasmid pGML10, either empty or encoding the indicated galactose-inducible $X$. campestris pv. vesicatoria effectors with a C-terminal myc tag, were grown overnight in repressing medium ( $2 \%$ glucose). Cultures were then diluted to an optical density at $600 \mathrm{~nm}$ of 1.0 , and serial 10 -fold dilutions were spotted onto repressing or inducing medium ( $2 \%$ galactose and $1 \%$ raffinose). Photographs were taken after 2 and 3 days of growth at $30^{\circ} \mathrm{C}$ for yeast growing in repressing and inducing medium, respectively. Data shown are representative of three independent experiments for each effector. 
growth-inhibition phenotype: XopX and AvrRxo1 completely inhibited yeast growth; XopB, XopE1, and XopF2 showed intermediate growth inhibition; and XopC and AvrBsT caused only a moderate yet significant growth-inhibition phenotype.

Expression of $X$. campestris pv. vesicatoria type III effectors in yeast under stress conditions

reveals additional growth-inhibition phenotypes.

Bacterial type III effectors may target conserved eukaryotic processes that are normally not rate limiting for yeast growth. In this scenario, compounds or environmental conditions that alter yeast cellular functions (hereafter called stressors) may increase yeast sensitivity to effectors and aid in the identification of effector-induced growth-inhibition phenotypes (Siggers and Lesser 2008). Based on this premise, we performed a screen for $X$. campestris pv. vesicatoria effectors that inhibit yeast growth in the presence of various stressors. To this aim, vectors for GAL1-driven expression of the $X$. campestris pv. vesicatoria type III effectors were introduced into the BY4741 and W303 yeast strains, which have slightly different genetic backgrounds and, thus, can be differentially affected by effectors and stressors. Yeast cultures were serially diluted and plated onto repressing or inducing media in the presence or absence of the following stressors at levels that minimally impact yeast growth: the purine analog caffeine (7 mM) (Kuranda et al. 2006), sodium chloride $(0.5 \mathrm{M})$ or sorbitol $(1 \mathrm{M})$ (Yoon et al. 2003), the inhibitor of protein glycosylation tunicamycin $(0.12 \mu \mathrm{g} / \mathrm{ml})$ (Kuo and Lampen 1974), and temperature of $37^{\circ} \mathrm{C}$. Growth of yeast expressing $X$. campestris pv. vesicatoria effectors was monitored and scored based on the highest dilution in which colonies were detected. Combining the expression of effectors with stress conditions enhanced growth-inhibition phenotypes detected for certain effectors in normal conditions (Fig. 2). For example, phenotypes induced by expression of XopE1, XopF2, XopB, AvrBsT, and XopC in the BY4741 yeast strain were significantly enhanced in the presence of caffeine. Similarly, growth inhibition caused by expression of XopX, XopE1, XopF2, and XopB in the W303 yeast strain were significantly enhanced in the presence of caffeine, sodium chloride, tunicamycin, and at $37^{\circ} \mathrm{C}$. More importantly, in the presence of various stressors, several growth-inhibition phenotypes were detected for effectors that do not affect yeast growth under normal conditions. For example, expression of XopQ strongly inhibited growth of BY4741 cells in the presence of caffeine while XopC and XopE2 inhibited growth of W303 cells in the presence of sodium chloride and caffeine, respectively. In addition, several effectors in different conditions caused mild growth-inhibition phenotypes (Fig. 2). Taken together, these analyses identified stress conditions for detection of growth inhibition caused by $X$. campestris pv. vesicatoria type III effectors in yeast and significantly enlarged the pool of phenotypes available for the functional characterization of these effector proteins.

Fig. 2. Yeast growth-inhibition phenotypes induced by Xanthomonas campestris pv. vesicatoria type III effectors under various growth conditions. A, BY4741 and B, W303 yeast strains carrying plasmids for the expression of the indicated effectors or containing an empty vector were grown overnight in repressing medium ( $2 \%$ glucose). Cultures were then washed and normalized to an optical density at $600 \mathrm{~nm}$ of 1.0 , and 10-fold serial dilutions were spotted onto repressing medium or onto inducing medium (2\% galactose and 1\% raffinose) and grown under the following stress conditions: in the presence of $7 \mathrm{mM}$ caffeine (Caff), $0.5 \mathrm{M}$ sodium chloride $(\mathrm{NaCl}), 1 \mathrm{M}$ sorbitol (Sorb), tunicamycin at $0.12 \mu \mathrm{g} / \mathrm{ml}(\mathrm{Tm})$, or temperature of $37^{\circ} \mathrm{C}$. At 2 to 4 days after spotting, the highest dilutions in which colony-growth was visible were determined for each strain and reported according to the indicated growth scale.
Expression of XopE1, XopX, and AvrRxo1 causes loss of viability in yeast.

We then tested whether growth-inhibition phenotypes caused by $X$. campestris pv. vesicatoria effectors in normal growth conditions were a result of cytotoxicity or arrest of cell growth. To this end, we performed cell viability assays for yeast strains expressing AvrRxo1, XopX, XopE1, XopF2, or $\mathrm{XopB}$. In these experiments, yeast cultures expressing effectors were sampled at different time points after induction and serial 10 -fold dilutions were plated onto repressing media to

\section{A BY4741}

\begin{tabular}{|c|c|c|c|c|c|c|}
\hline & \multicolumn{6}{|c|}{ Stress } \\
\hline Effector & None & Caff & $\mathrm{NaCl}$ & Sorb & $\mathrm{Tm}$ & $37^{\circ} \mathrm{C}$ \\
\hline Empty & & & & & & \\
\hline AvrRxo1 & & & & & & \\
\hline XopX & & & & & & \\
\hline XopE1 & & & & & & \\
\hline XopF2 & & & & & & \\
\hline XорB & & & & & & \\
\hline AvrBsT & & & & & & \\
\hline XopC & & & & & & \\
\hline XopE2 & & & & & & \\
\hline XopQ & & & & & & \\
\hline ecf & & & & & & \\
\hline AvrBs1 & & & & & & \\
\hline XopD & & & & & & \\
\hline AvrBs3 & & & & & & \\
\hline XopF1 & & & & & & \\
\hline XopJ & & & & & & \\
\hline XopN & & & & & & \\
\hline XорО & & & & & & \\
\hline XopP & & & & & & \\
\hline AvrRxv & & & & & & \\
\hline AvrBs2 & & & & & & \\
\hline AvrXv4 & & & & & & \\
\hline
\end{tabular}

\section{B W303}

\begin{tabular}{|c|c|c|c|c|c|c|}
\hline & \multicolumn{6}{|c|}{ Stress } \\
\hline Effector & None & Caff & $\mathrm{NaCl}$ & Sorb & $\mathrm{Tm}$ & $37^{\circ} \mathrm{C}$ \\
\hline \multicolumn{7}{|l|}{ Empty } \\
\hline \multicolumn{7}{|l|}{ AvrRxo1 } \\
\hline \multicolumn{7}{|l|}{ XopX } \\
\hline \multicolumn{7}{|l|}{ XopE1 } \\
\hline \multicolumn{7}{|l|}{ XopF2 } \\
\hline \multicolumn{7}{|l|}{ ХорВ } \\
\hline \multicolumn{7}{|l|}{ AvrBsT } \\
\hline \multicolumn{7}{|l|}{ XopC } \\
\hline \multicolumn{7}{|l|}{ XopE2 } \\
\hline \multicolumn{7}{|l|}{ XopQ } \\
\hline \multicolumn{7}{|l|}{ ecf } \\
\hline \multicolumn{7}{|l|}{ AvrBs1 } \\
\hline \multicolumn{7}{|l|}{ XopD } \\
\hline \multicolumn{7}{|l|}{ AvrBs3 } \\
\hline \multicolumn{7}{|l|}{ XopF1 } \\
\hline \multicolumn{7}{|l|}{ XopJ } \\
\hline \multicolumn{7}{|l|}{ XopN } \\
\hline \multicolumn{7}{|l|}{ XopO } \\
\hline \multicolumn{7}{|l|}{ XopP } \\
\hline \multicolumn{7}{|l|}{ AvrRxv } \\
\hline \multicolumn{7}{|l|}{ AvrBs2 } \\
\hline AvrXv4 & & & & & & \\
\hline
\end{tabular}

Degree of growth:

No growth in any dilution

up to the $10^{0}$ dilution $\square$ up to the $10^{-1}$ dilution

$\square$ up to the $10^{-2}$ dilution $\square$ up to the $10^{-3}$ dilution 
determine the number of viable cells present in the cultures. A constant number of viable cells over time was observed for strains expressing XopB or XopF2 (Fig. 3), suggesting that these effectors cause a reduction in cell proliferation. However, a sharp decrease in the number of viable cells over time was detected for yeast expressing AvrRxo1, and a more gradual reduction in viability was detected for yeast expressing XopX or XopE1 (Fig. 3). These results suggest that expression of AvrRxo1, XopX, or XopE1 induces different degrees of cytotoxicity in yeast.

\section{Expression of AvrRxo1 and XopX}

\section{in yeast arrests the cell cycle at the G0/1 phase.}

We next explored whether $X$. campestris pv. vesicatoria type III effectors that cause growth-inhibition phenotypes in yeast in the absence of stressors may affect the cell cycle. To test this possibility, we examined cell morphologies of yeast cultures expressing AvrRxo1, XopX, XopE1, XopF2, or XopB, and estimated the proportion of cells with no bud and with bud of various sizes compared with a yeast strain containing an empty vector. Yeast expressing XopB, XopE1, and XopF2 displayed

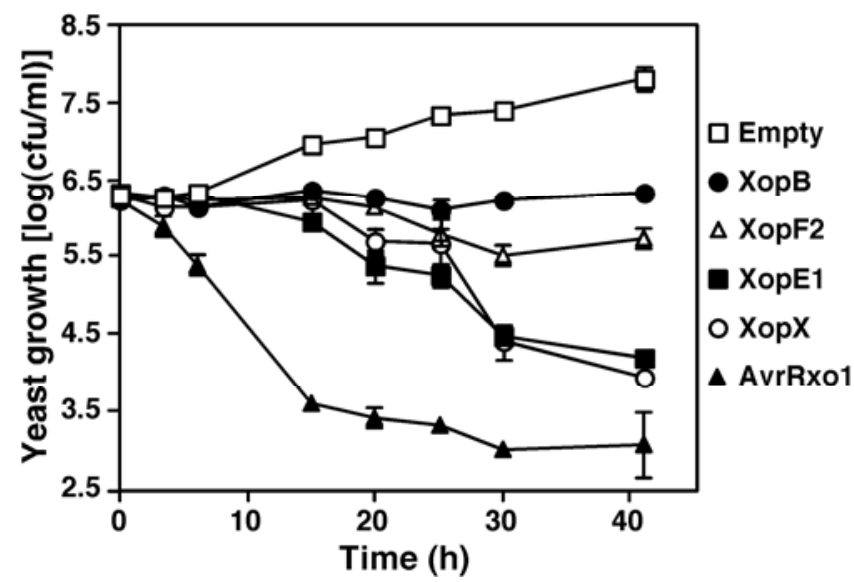

Fig. 3. Cell viability assays of yeast strains expressing Xanthomonas campestris pv. vesicatoria type III effectors that inhibit yeast growth. BY4741 yeast strains carrying plasmids for expression of the indicated effectors or containing an empty vector were grown overnight in repressing medium ( $2 \%$ glucose). Cultures were diluted to an optical density at $600 \mathrm{~nm}$ $\left(\mathrm{OD}_{600}\right)$ of 0.5 and allowed to recover in fresh repressing medium for $2 \mathrm{~h}$ prior to washes, normalization to $\mathrm{OD}_{600}=0.2$, and incubation in inducing medium ( $2 \%$ galactose and $1 \%$ raffinose). For each time point, an aliquot was removed from the cultures and serial 10-fold dilutions were spotted onto repressing medium to assess the number of viable cells. Data represent the mean and standard error $(n=3)$. The assay was repeated three times with similar results.

Fig. 4. Morphology and DNA content of yeast cells expressing Xanthomonas campestris pv. vesicatoria type III effectors that inhibit yeast growth A, BY4741 yeast strains carrying plasmids for expression of the indicated effectors or containing an empty vector were grown overnight in repressing medium ( $2 \%$ glucose). Cells were washed, diluted, and grown overnight in inducing medium ( $2 \%$ galactose and $1 \%$ raffinose). Induced cultures were briefly sonicated and cell morphology was visualized under the microscope. B, Percentage of the different morphologies (cells with no bud, small bud, medium bud, or large bud) in the cell population was assessed for each yeast strain. Data are the mean and standard error of three independent experiments $(n>150)$. Asterisks represent statistically significant differences between the proportion of cells with no bud in yeast expressing effectors compared with the control strain based on analysis of variance and comparisons for all pairs using Tukey-Kramer honestly significance difference $(P<0.005)$. C, DNA content of induced cells analyzed by fluorescenceactivated cell sorting after cell fixing and staining by propidium iodide. The experiment was repeated three times with similar results. only a marginal increase in the proportion of unbudded cells (Fig. 4A and B). However, expression of AvrRxo1 or XopX resulted in a significant increase in the proportion of unbudded cells to approximately $80 \%$ compared with approximately $40 \%$ in yeast containing an empty vector $(\mathrm{P}<0.005)$ (Fig. $4 \mathrm{~A}$ and $\mathrm{B})$.

Accumulation of unbudded cells may indicate that the yeast culture is arrested at the G0/1 phase of the cell cycle prior to DNA replication. To determine whether unbudded yeast cells in cultures expressing XopX or AvrRxo1 had undergone DNA replication or are arrested at the G0/1 phase of the cell-cycle, we quantified their DNA content using flow cytometry (fluorescence-activated cell sorting [FACS]) compared with yeast cells carrying an empty vector or expressing other effectors. In
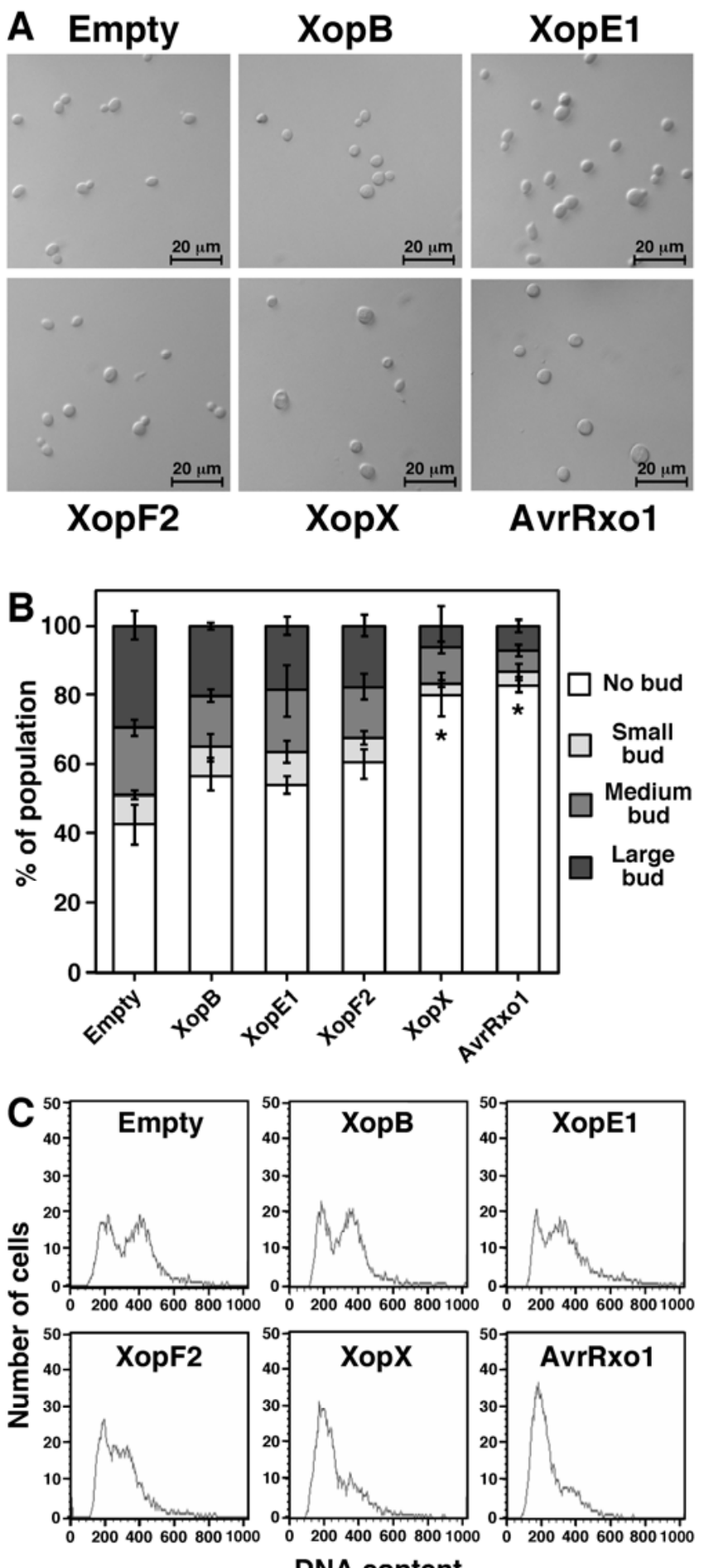

DNA content 
agreement with the morphological observations, $1 \mathrm{~N}$ and $2 \mathrm{~N}$ DNA peaks were observed for yeast cultures carrying an empty vector or expressing XopB, XopE1, or XopF2 (Fig. 4C). However, only a predominant 1 N DNA peak was detected for yeast cultures expressing XopX and AvrRxo1, suggesting that the majority of the cells were arrested at the G0/1 phase of the cell cycle and did not complete DNA replication. Together, these results indicate that expression of XopX and AvrRxo1 in yeast affects cellular functions required for the proper transition from $\mathrm{G} 0 / 1$ to the $\mathrm{S}$ phase of the cell cycle.

\section{$X$. campestris pv. vesicatoria type III effectors that cause growth inhibition in yeast} induce various phenotypes in host and nonhost plants.

Once it was established that AvrRxo1, XopX, XopE1, $\mathrm{XopF} 2$, and XopB can perturb yeast cellular functions, we analyzed whether these type III effectors can cause detectable phenotypes in host and nonhost plants. In these experiments, we used Agrobacterium spp. to transiently express effectors under control of the Cauliflower mosaic virus (CaMV) 35S promoter in leaves of tomato (Solanum lycopersicum) and Nicotiana benthamiana plants, which are host and nonhost of $X$. campestris pv. vesicatoria bacteria, respectively. Effectors were tagged at their $\mathrm{C}$ terminus and accumulation in planta was confirmed by immunoblot analysis for all of them except XopE1 (Supplementary Fig. S2), which was previously reported to be expressed at low levels in leaves (Thieme et al. 2007). Expression of XopX and XopF2 resulted in a cell-death phenotype that developed fast (within 2 to 3 days after agroinfiltration) and covered the entire infiltrated area in leaves of both host and nonhost plants (Fig. 5). A milder phenotype was caused in both plant backgrounds by expression of AvrRxo1 and consisted of chlorosis and patches of cell death in the infiltrated leaf areas that appeared within 3 to 4 days after agroinfiltration. Interestingly, differential phenotypes were observed for XopB and XopE1 in host and nonhost plants. XopB caused a fast and confluent cell death when expressed in the nonhost $N$. benthamiana leaves, whereas its expression in tomato did not result in a visible phenotype, even 7 days after agroinfiltration. Similarly, upon XopE1 expression in N. benthamiana leaves, chlorosis appeared in infiltrated areas within 5 days and eventually developed into cell death after 7 days, thus confirming observations reported by Thieme and associates (2007). Interestingly, expression of XopE1 in tomato leaves resulted in the appearance of sporadic cell-death patches. Taken together, these results indicate that expression in leaves of $X$. campestris pv. vesicatoria type III effectors that cause growth inhibition in yeast results in the appearance of various phenotypes that are dependent on the plant genetic background.

\section{Localization motifs and putative catalytic residues are required for the ability of $X$. campestris pv. vesicatoria effectors to induce phenotypes in yeast.}

Next, we asked whether the ability of $X$. campestris pv. vesicatoria type III effectors to induce phenotypes in yeast is dependent on their molecular properties. To this end, we tested whether the correct intracellular localization of XopE1 and XopE2 and putative catalytic activities of XopE1, XopE2, and $\mathrm{XopC}$ are required for their ability to inhibit yeast growth. XopE1 and XopE2 are members of the HopX family of putative transglutaminases and localize to the plasma membrane of plant cells as a result of myristoylation (Thieme et al. 2007). Based on the putative catalytic residues described for HopX, the $P$. syringae prototype of the HopX family of effectors (Nimchuk et al. 2007), we identified corresponding putative catalytic residues in XopE1 and XopE2 as Asp215 and Asp211, respectively (Supplementary Fig. S3A). We then tested whether alanine substitutions of these aspartic acid residues or of the glycine residue at amino acid position 2 of XopE1 and XopE2 myristoylation sites affect the ability of these effectors to inhibit yeast growth. A mutation in the putative XopE1 catalytic residue (D215A) completely impaired the ability of this effector to inhibit yeast growth in normal conditions or in the presence of caffeine (Fig. 6A). Accordingly, the same mutation compromised the development of cell death that is observed in $N$. benthamiana leaf areas expressing wild-type XopE1 (Fig. $6 \mathrm{~B})$. However, a mutation at the XopE1 myristoylation site (G2A) decreased only mildly growth inhibition resulting from XopE1 expression (Fig. 6A). In agreement with this observation, a G2A substitution in XopE1 did not reduce the cell death triggered by this effector in $N$. benthamiana plants (Thieme et al. 2007). Expression of XopE1 $1^{\mathrm{D} 215 \mathrm{~A}}$ both in yeast and in planta was confirmed by Western blot analysis. However, expression of the wild-type XopE1 and XopE1 ${ }^{\mathrm{G} 2 \mathrm{~A}}$ were below detection levels despite their ability to cause phenotypes (Sup-
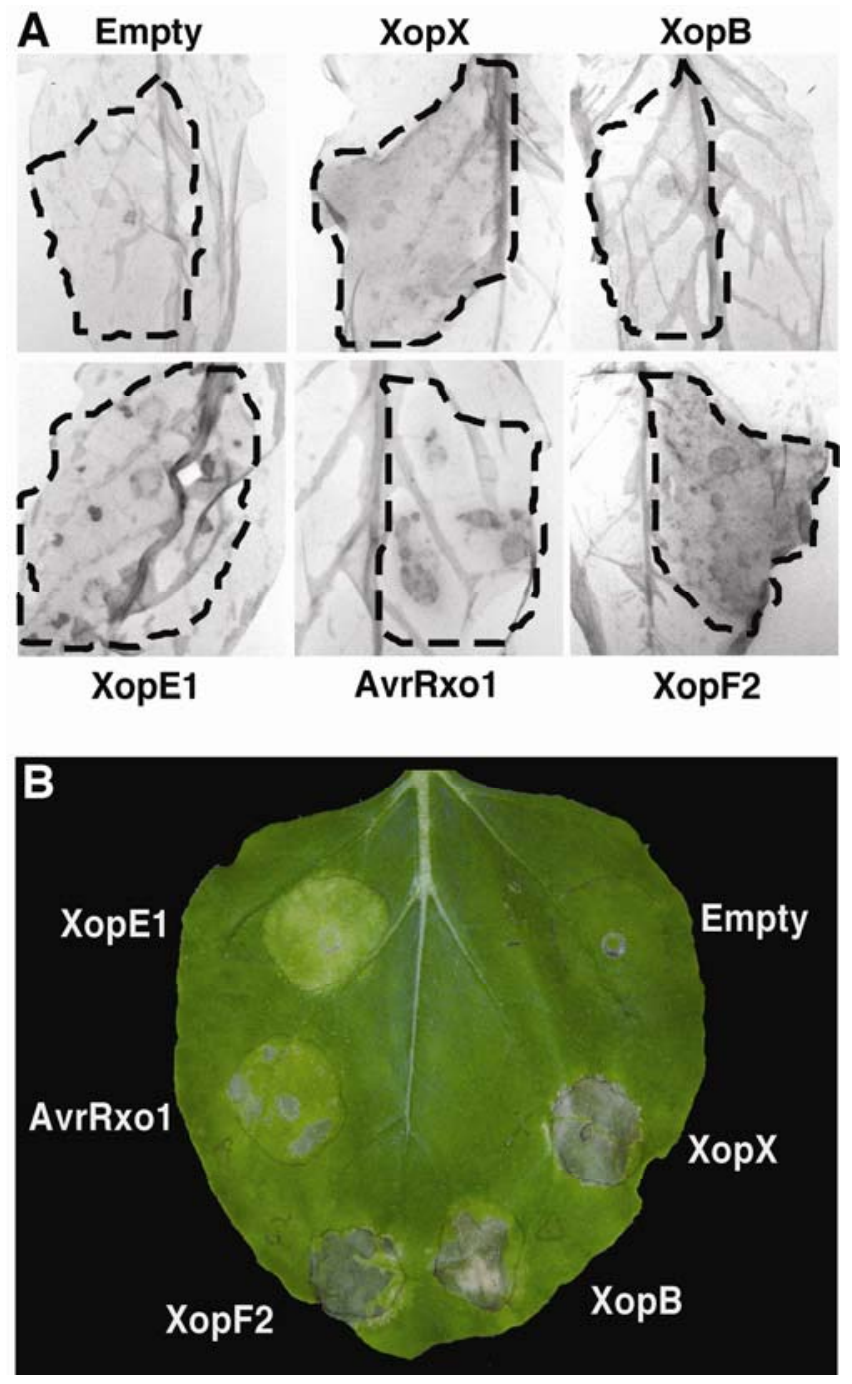

Fig. 5. Phenotypes induced in plants by expression of Xanthomonas campestris pv. vesicatoria type III effectors that inhibit yeast growth. XopE1, XopB, XopX, AvrRxo1, and XopF2 were expressed under the control of the Cauliflower mosaic virus $35 \mathrm{~S}$ promoter in leaves of $\mathbf{A}$, tomato or B, Nicotiana benthamiana plants via Agrobacterium spp.-mediated transient expression. Tomato leaves were bleached in chlorophyll destaining solution for better visualization of cell death (dark gray areas). Pictures were taken 5 days after agroinfiltration. The experiment included at least five technical repeats for each treatment and was repeated three times with similar results. 
plementary Fig. S4A and B). In contrast to XopE1, a mutation in the myristoylation site of XopE2 (G2A) but not in the putative catalytic aspartic acid (D211A) abolished the growth-inhibition phenotype induced by this effector in the presence of caffeine (Fig. 6C). Expression of XopE2, XopE2 ${ }^{\mathrm{G} 2 \mathrm{~A}}$, and XopE2 $2^{\text {D211A }}$ was confirmed by Western blot analysis. As previously reported (Thieme et al. 2007), in this analysis, XopE2 ${ }^{\mathrm{G} 2 \mathrm{~A}}$ showed a reduced molecular weight compared with wild-type XopE2, possibly due to myristoylation-dependent posttranslational modifications. These results suggest that catalytic activity for XopE1 and myristoylation for XopE2 are molecular properties required for their ability to induce phenotypes in yeast. In addition, the catalytic activity of XopE1 is also required for induction of chlorosis and cell death in plants.

We next explored the requirement of a putative XopC catalytic residue for yeast growth inhibition caused by this effector. A search in the National Center for Biotechnology Information conserved domain database (Marchler-Bauer et al. 2009) revealed that XopC contains a putative haloacid dehalogenase (HAD)-like hydrolase domain in its C-terminal end. In several instances, proteins containing an HAD-like hydrolase domain were shown to be phosphohydrolases that use a nucleophylic aspartic acid in the phosphoryl transfer reaction (Calderone et al. 2006; Lahiri et al. 2006). By an alignment of the XopC C terminus with homologous domains of other proteins, we identified a conserved aspartic acid residue at position 693 and hypothesized that it may represent a key catalytic residue required for XopC putative enzymatic activity. We then substi- tuted this residue with an alanine (D693A) and tested the ability of the mutant protein to inhibit growth in yeast in presence of caffeine. Expression of $\mathrm{XopC}^{\mathrm{D} 693 \mathrm{~A}}$ did not cause a growthinhibition phenotype in yeast as opposed to the wild-type protein (Fig. 6C), suggesting that HAD-like hydrolase activity is required for the XopC deleterious effect in yeast. Expression of XopC and XopC ${ }^{\mathrm{D} 693 \mathrm{~A}}$ was confirmed by Western blot analysis. Taken together, these results indicate that growth-inhibition phenotypes observed in yeast are linked to molecular properties of the tested effectors.

\section{DISCUSSION}

In this study, we screened a group of $X$. campestris pv. vesicatoria type III effectors for their ability to inhibit yeast growth. Phenotypes were detected for 14 of the 21 effectors tested $(66 \%)$. In a similar screen of $P$. syringae pv. tomato effectors, 7 of the 27 effectors tested (26\%) significantly inhibited yeast growth (Munkvold et al. 2008). The higher proportion of phenotypes detected for $X$. campestris pv. vesicatoria effectors is largely due to the employment in our screen of various compounds or conditions that alter yeast cellular functions (stressors) and assist in the investigation of effectors that are normally not rate-limiting for yeast proliferation. The synergistic action of stressors and effectors may be the result of effector interference with a cellular process parallel and redundant with the process affected by the stressor. Alternatively, the effector could interfere with a cellular process required to sus-
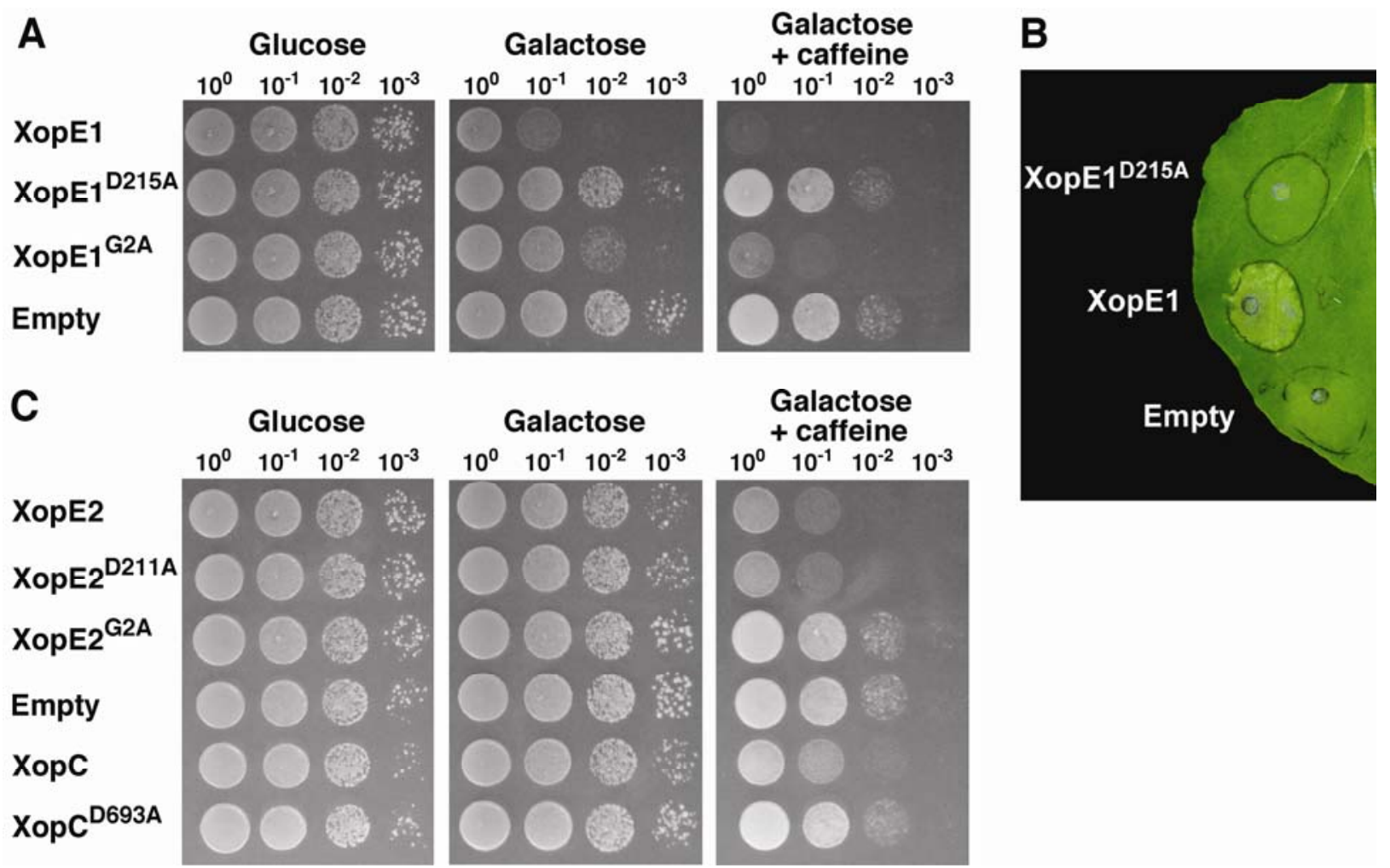

Fig. 6. Effect of mutations in putative catalytic residues and intracellular localization motifs of Xanthomonas campestris pv. vesicatoria effectors on phenotypes induced in yeast and plants. A, W303 yeast strains expressing wild-type or mutant forms of XopE1 were grown overnight in repressing medium (2\% glucose). Cultures were then washed and normalized to an optical density at $600 \mathrm{~nm}$ of 1.0, and 10-fold serial dilutions were spotted onto repressing medium or inducing medium ( $2 \%$ galactose and $1 \%$ raffinose) with or without $7 \mathrm{mM}$ caffeine. Pictures were taken after 2,3 , and 4 days of growth at $30^{\circ} \mathrm{C}$ for yeast growing on repressing medium, inducing medium, and inducing medium with caffeine, respectively. B, XopE1 and XopE1 ${ }^{\mathrm{D} 215 \mathrm{~A}}$ were expressed under the control of the Cauliflower mosaic virus $35 \mathrm{~S}$ promoter in leaves of $N$. benthamiana plants via Agrobacterium spp.-mediated transient expression. Infiltrated areas are marked with black circles. Pictures were taken 5 days after agroinfiltration. The experiment included at least five technical repeats for each treatment and was repeated three times with similar results. C, W303 yeast strains expressing wild-type or mutant forms of XopE2 and XopC were grown and treated as described in A. Pictures were taken after 2,3 , and 4 days of growth at $30^{\circ} \mathrm{C}$ for yeast growing on repressing medium, inducing medium, and inducing medium with caffeine, respectively. 
tain growth and viability under stress conditions. In fact, seven of the $X$. campestris pv. vesicatoria effectors tested (XopB, XopC, XopE1, XopF2, XopX, AvrBsT, and AvrRxo1) inhibited yeast growth in normal conditions, and seven additional effectors (XopD, XopE2, XopQ, ecf, AvrRxv, AvrBs1, and AvrBs3) inhibited yeast growth only in the presence of stressors. Similarly, in a screen of Shigella effectors, 4 of the 18 effectors tested $(21 \%)$ inhibited yeast growth in normal conditions, whereas 5 additional effectors showed a phenotype only in the presence of stressors, increasing to $50 \%$ the total proportion of effectors that caused growth inhibition (Slagowski et al. 2008).

The employment of two genetically distinct yeast strains, BY4741 and W303, also contributed to the large spectrum of phenotypes observed in this study. In several instances, the severity of growth inhibition caused by effectors differed in the two strains and, in others, phenotypes were specific only to a certain strain. Genetic analysis estimated a $0.08 \%$ nucleotide divergence between the BY4741 and W303 strains, and revealed seven deletions of at least $500 \mathrm{bp}$ in W303 compared with BY4741 (Schacherer et al. 2007). A known difference between the genetic backgrounds of W303 and BY4741 is a polymorphism at the SSD1 locus, which functions to promote cell-wall integrity (Kaeberlein and Guarente 2002). Because caffeine is known to cause cell-wall stress (Kuranda et al. 2006), polymorphism at the SSD1 locus could account for the higher number (12) of effectors that caused growth inhibition when expressed in W303 in the presence of caffeine compared with the number of effectors (nine) causing a phenotype in BY4741 under the same conditions. In the presence of tunicamycin, more effectors inhibited growth in BY4741 (11) than in W303 (eight). This result is unexpected because the W303 strain was previously reported to be more sensitive to tunicamycin than BY4741 (Dudgeon et al. 2008). The use of additional stressors and yeast strains with various genetic backgrounds may further enhance the severity of growth inhibition caused by $X$. campestris pv. vesicatoria effectors in yeast or assist in detecting new phenotypes. In addition, conditional sensitivity to particular stressors can provide clues as to the cellular pathways targeted by the effector proteins. For example, sensitivity to tunicamycin can be due to targeting of the host secretory pathway (Back et al. 2005), whereas sensitivity to sorbitol and salt may suggests a perturbation of mitogen-activated protein kinase cascades, such as the high osmolarity growth pathway (Yoon et al. 2003).

Further examination of the growth-inhibition phenotypes caused by AvrRxo1 and XopX revealed that these two effectors arrest the yeast cell cycle at the G0/1 phase and cause loss of cell viability. Several type III effectors from bacterial pathogens of animals were previously shown to arrest the cell cycle. For example, the CopN effector of Chlamydia pneumoniae arrests the yeast cell cycle at the G2/M phase, presumably by causing alterations in the microtubule cytoskeleton (Huang et al. 2008). Similarly, a family of homologous proteins from human pathogens, including Escherichia coli and Yersinia, Photorabdus, and Bukholderia spp., arrest the host cell cycle at $\mathrm{G} 2 / \mathrm{M}$ by using papain-like hydrolytic activity (Yao et al. 2009). In yeast, hyperosmotic and oxidative stress or interference with several signaling pathways, such as those regulated by the PKA, CDK, and TOR kinases, can result in arrest of the cell cycle at the G0/1 phase (Barbet et al. 1996; Mendenhall and Hodge 1998; Tokiwa et al. 1994). However, prolonged cell cycle arrest at the G0/1 phase does not necessarily lead to loss of cell viability (Gerald et al. 2002; Maayan and Engelberg 2009). It remains to be determined which molecular processes are affected by AvrRxo1 and XopX expression in yeast and their corresponding targets in plants.
The XopE1, XopF2, XopX, and AvrRxo1 effectors, which in normal conditions caused the most severe inhibition of yeast growth, caused phenotypes ranging from chlorosis to cell death when transiently expressed via Agrobacterium spp. in tomato and $N$. benthamiana leaves. These phenotypes can be ascribed either to the virulence activity of the effectors in plant cells or to their recognition by the plant surveillance system. The latter possibility is less likely for the cell death observed in tomato plants because the $X$. campestris pv. vesicatoria $85-$ 10 strain, from which the four effectors derive, is virulent in the tomato line used in our experiments, strongly supporting the notion that, in this plant, effectors of $X$. campestris pv. vesicatoria 85-10 are not efficiently recognized by any $\mathrm{R}$ protein. Yet, it is possible that, in the whole bacterial context, these effectors have a latent avirulence activity which is suppressed by other effectors, as recently suggested for certain Ralstonia and Pseudomonas effectors (Wroblewski et al. 2009). Conversely, expression of the XopB effector, which inhibits yeast growth less severely than XopE1, XopF2, XopX, and AvrRxo1, caused cell death in $N$. benthamiana leaves but not in tomato, suggesting that this effector is specifically recognized by an $N$. benthamiana $\mathrm{R}$ protein. Alternatively, XopB might affect a cellular target found in $N$. benthamiana but not in tomato. This is unlikely considering the fact that tomato but not $N$. benthamiana is a natural host of $X$. campestris pv. vesicatoria.

Our results that Agrobacterium spp.-mediated expression of XopX in $N$. benthamiana leaves causes cell death is in apparent contradiction with a previous report showing that Agrobacterium spp.-mediated expression of XopX from $X$. campestris pv. vesicatoria GM98, which is identical to that of the $X$. campestris pv. vesicatoria 85-10 strain, does not induce cell death unless it is expressed in the presence of $X$. campestris pv. vesicatoria $\triangle x o p X$ bacteria with an intact T3SS (Metz et al. 2005). This and accompanying evidence described in the same report support the conclusion that XopX possesses virulence but not avirulence activity in $N$. benthamiana plants. The ability of our system to detect the virulence activity of XopX, when expressed alone in $N$. benthamiana plants, may be derived from a difference in the constructs used for expression (e.g., different epitope tags) or in the infection efficiency of the employed Agrobacterium strains that may affect protein expression levels or stability. In addition, it is possible that, in our system, plant physiological responses are more readily activated. In support of this possibility, in our system, lower titers of $X$. campestris pv. vesicatoria bacteria are sufficient to induce cell death in $N$. benthamiana leaves compared with the titers reported by Metz and associates (2005) $\left(10^{7}\right.$ versus $4 \times 10^{8}$ $\mathrm{CFU} / \mathrm{ml})$.

Mutagenesis of putative catalytic residues (for XopC, XopE1, and XopE2) or myristoylation sites (for XopE1 and XopE2) and analysis of the ability of the derived mutants to inhibit yeast growth support the notion that yeast represent a suitable system to study molecular properties of $X$. campestris pv. vesicatoria effectors. A mutation at the aspartic acid putative catalytic residue of XopE1 abolished the growth inhibition phenotype and cell death caused by expression of this effector in yeast and plants, respectively. It should be noted that, although XopE1 Asp215 is a candidate catalytic residue, the increased expression level of the XopE1 ${ }^{\mathrm{D} 215 \mathrm{~A}}$ that was observed in immunoblots could possibly suggest improper folding of the mutant protein. A mutation at the XopE1 myristoylation site did not prevent the effector from inhibiting yeast growth nor, as reported by Thieme and associates (2007), did it impair XopE1-mediated cell death in plants. These results establish a correlation between the effect of mutations on the phenotypes caused by XopE1 in yeast and in plants. Interestingly, and in contrast to its homolog XopE1, a 
mutation at the XopE2 myristoylation site but not at the aspartic acid putative catalytic residue compromised yeast growth inhibition caused by XopE2 in the presence of caffeine. This evidence, together with the requirement of caffeine to detect the effect on yeast growth of XopE2 but not of XopE1, strongly suggest that these two HopX family members have different modes of action in eukaryotic cells despite their high degree of homology. The inability of a XopC effector mutated at a putative catalytic residue to inhibit yeast growth supports an important function for the HAD-like hydrolase domain of this protein. However, the catalytic activity of this domain and its relationship with a putative phosphorybosyl-transferase domain also present in XopC remain to be determined.

Yeast phenotypes identified in this study, including growth inhibition caused by different effectors and cell cycle arrest caused by AvrRxo1 and XopX, will assist in the search for eukaryotic targets of $X$. campestris pv. vesicatoria effectors. Proteins that, upon overexpression, suppress phenotypes caused by effectors in yeast may represent either direct targets of the effectors or proteins that participate in cellular processes affected by the effector in question. Cell-death phenotypes induced in plants by various effectors, such as XopE1, XopF2, XopX, AvrRxo1, and XopB, will be used to verify putative targets by overexpression or silencing techniques. We expect that the use of yeast in the study of $X$. campestris pv. vesicatoria type III effectors will provide insight into effector functions and strategies of bacterial pathogenesis.

\section{MATERIALS AND METHODS}

\section{Media and bacterial and yeast strains.}

Bacteria used in this study were E. coli $\mathrm{DH} 12 \mathrm{~S}$, Agrobacterium tumefaciens $\mathrm{GV} 2260$, X. campestris pv. vesicatoria race T1 strain $85-10, X$. campestris pv. vesicatoria race T1 strain 75-3, X. campestris pv. vesicatoria race T3 strain 97-2, and $X$. campestris pv. vesicatoria race $\mathrm{P} 1$ strain 116 . E. coli and $A$. tumefaciens bacteria were grown in Luria-Bertani broth (LB) (Sambrook et al. 1989) supplemented with the appropriate antibiotics at 37 and $28^{\circ} \mathrm{C}$, respectively. The following antibiotics concentrations were used: ampicillin, $100 \mu \mathrm{g} / \mathrm{ml}$; kanamycin, $50 \mu \mathrm{g} / \mathrm{ml}$; and rifampicin, $100 \mu \mathrm{g} / \mathrm{ml}$. X. campestris pv. vesicatoria strains were grown in nutrient yeast glycerol media (Daniels et al. 1984) supplemented with rifampicin at $100 \mu \mathrm{g} / \mathrm{ml}$ and $28^{\circ} \mathrm{C}$.

Yeast strains used for expression of $X$. campestris pv. vesicatoria type III effectors were BY4741 (MATa his3 41 leu2 $\Delta O$ met15 $\Delta 0$ ura3 $\Delta O$ ) and W303 (MATa, leu2-3,112 trp1-1 can1100 ura3-1 ade2-1 his3-11,15). Yeast were grown at $30^{\circ} \mathrm{C}$ in YPD medium (1\% yeast extract, $2 \%$ peptone, $2 \%$ glucose) or in selective synthetic complete media (Salomon and Sessa 2010) lacking leucine (-leu) to maintain the plasmid, and supplemented with $2 \%$ glucose or $2 \%$ galactose and $1 \%$ raffinose as carbon sources.

\section{Plasmid constructions.}

All X. campestris pv. vesicatoria effector genes were PCR amplified using Ex-Taq DNA polymerase (Takara Bio, Madison, WI, U.S.A.) from $X$. campestris pv. vesicatoria race T1 strain 85-10 genomic DNA, except for $a v r B s T$, $a v r X v 4$, and $a v r B s 3$, which were amplified from $X$. campestris pv. vesicatoria race T1 strain 75-3, X. campestris pv. vesicatoria race T3 strain 97-2, and $X$. campestris pv. vesicatoria race $\mathrm{P} 1$ strain 116 , respectively. Sequences of oligonucleotides used for amplification of effectors are listed in Supplementary Table S1. Amplified effectors were inserted in frame to a c-myc tag into the multiple cloning site of the pGML10 yeast expression vector (RIKEN website) under the control of a galactose-inducible promoter.
Site-directed mutagenesis of xopE1, xopE2, and xopC was performed in pGML10 plasmids using the Quickchange kit (Stratagene, La Jolla, CA, U.S.A.) and the oligonucleotides listed in Supplementary Table S2. The presence of the desired mutations was confirmed by DNA sequencing.

For expression in plants, the c-myc tagged $X$. campestris pv. vesicatoria effector genes $x о p B, x o p E 1, x o p E 1^{D 215 A}, x o p F 2$, $x o p X$, and avrRxol were excised from the pGML10 vector and inserted at the multiple cloning site of the binary vector pBTEX under control of the CaMV 35S promoter (Frederick et al. 1998).

\section{Yeast growth inhibition assays.}

pGML10-based expression vectors carrying $X$. campestris pv. vesicatoria effectors were transformed into the Saccharomyces cerevisiae strains BY4741 and W303 by the lithium acetate transformation method (Gietz et al. 1992). Transformed yeast were plated onto selective synthetic complete-leu media (hereafter called selective media) supplemented with $2 \%$ glucose. Growth-inhibition assays were performed as previously described (Salomon and Sessa 2010). In brief, yeast cultures were grown overnight at $30^{\circ} \mathrm{C}$ in liquid selective media containing $2 \%$ glucose, washed, and normalized to an optical density at $600 \mathrm{~nm}\left(\mathrm{OD}_{600}\right)$ of 1.0. Each strain was 10 -fold serially diluted four times and spotted $(10 \mu \mathrm{l})$ onto repressing $(2 \%$ glucose) or inducing ( $2 \%$ galactose and $1 \%$ raffinose) solid selective media, or onto inducing media supplemented with caffeine (7 $\mathrm{mM})$, sorbitol $(1 \mathrm{M})$, sodium chloride $(0.5 \mathrm{M})$ or tunicamy$\operatorname{cin}(0.12 \mu \mathrm{g} / \mathrm{ml})$. Yeast were then incubated at 30 or $37^{\circ} \mathrm{C}$ for 2 to 4 days.

For yeast viability plating assays, strains carrying pGML10based expression vectors carrying $X$. campestris pv. vesicatoria effectors were grown overnight in selective media containing glucose $(2 \%)$. Cultures were diluted to $\mathrm{OD}_{600}=0.5$ and allowed to recover in fresh repressing media for $2 \mathrm{~h}$, prior to normalization to $\mathrm{OD}_{600}=0.2$ and induction in media containing galactose $(2 \%)$ and raffinose $(1 \%)$. At different time points after induction, aliquots were removed, 10-fold serially diluted four times, and spotted $(10 \mu \mathrm{l})$ onto selective repressing medium. Plates were incubated for 2 days at $30^{\circ} \mathrm{C}$ before colonies were counted.

\section{Yeast microscopy and DNA content analysis.}

To determine the morphology of yeast expressing $X$. campestris pv. vesicatoria effectors, cultures were grown overnight at $30^{\circ} \mathrm{C}$ in selective media containing $2 \%$ glucose. Cultures were then washed, diluted, and grown overnight at $30^{\circ} \mathrm{C}$ in selective media containing galactose $(2 \%)$ and raffinose $(1 \%)$. Induced cultures were briefly sonicated and visualized with a light Zeiss Axioskop 2 microscope (Zeiss AG, Oberkochen, Germany). Images were acquired using a $\times 40$ objective and processed using the Axiovision software (Zeiss AG).

DNA content of yeast cultures expressing $X$. campestris pv. vesicatoria effectors was determined by FACS analysis as previously described (Hutter and Eipel 1979). In brief, 1 to $2 \times$ $10^{6}$ yeast cells grown in inducing media were collected and fixed by incubation in $70 \%$ ethanol for $1 \mathrm{~h}$. Cells were then washed in 0.2 M Tris (pH 7.0) and $20 \mathrm{mM}$ EDTA and treated with $0.1 \%$ RNAse A for $4 \mathrm{~h}$ at $37^{\circ} \mathrm{C}$. For DNA staining, treated cells were washed in phosphate buffered saline (PBS; $137 \mathrm{mM}$

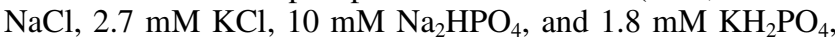
$\mathrm{pH}$ 7.4) and incubated overnight in PBS containing propidium iodide $(50 \mu \mathrm{g} / \mathrm{ml})$ at $4^{\circ} \mathrm{C}$. On the next day, DNA content was determined by FACS analysis.

\section{Agrobacterium spp.-mediated transient expression assay.}

pBTEX plasmids either empty or carrying the $X$. campestris pv. vesicatoria effector genes $x o p B, x o p E 1, x o p E 1^{D 215 A}, x o p F 2$, 
xopX, or avrRxol were transformed into A. tumefaciens GV2260 by electroporation. Transformed Agrobacterium strains were grown overnight at $28^{\circ} \mathrm{C}$ in $\mathrm{LB}$ with kanamycin at $50 \mu \mathrm{g} / \mathrm{ml}$ and rifampicin at $100 \mu \mathrm{g} / \mathrm{ml}$. Bacterial cultures were then diluted to an $\mathrm{OD}_{600}=0.06$ in infiltration medium $(10 \mathrm{mM}$ MES, $10 \mathrm{mM} \mathrm{MgCl} 2$, and $0.2 \mathrm{mM}$ acetosyringone) and infiltrated into leaves of 6- to 8-week-old $N$. benthamiana and tomato (Solanum lycopersicum) plants. The tomato line used in these experiments was Rio Grande PtoS (Pedley and Martin 2003). Infiltrated areas were monitored over the next 7 days. For better visualization of cell death, detached tomato leaves were treated with a chlorophyll destaining solution (60\% ethanol, $30 \%$ chloroform, and $10 \%$ acetic acid) and washed with a recovery solution (20\% ethanol, $20 \%$ glycerol, and $5 \%$ acetic acid) before photographs were taken.

\section{Protein extracts and immunoblotting.}

To verify expression of $X$. campestris pv. vesicatoria effectors in yeast, yeast cultures were grown and lysed as previously described (Salomon and Sessa 2010). Protein extracts were fractionated by sodium-dodecyl sulfate polyacrylamide gel electrophoresis (SDS-PAGE) and electroblotted onto nitrocellulose. Blots were probed with mouse anti-myc (clone 9E10) primary antibodies (1:1000; Santa Cruz Biotechnology, Santa Cruz, CA, U.S.A.) and horseradish peroxidase-conjugated goat anti-mouse secondary antibody (1:5000; Sigma Aldrich, St. Louis), and visualized by chemiluminescence (GE Healthcare, Little Chalfont, U.K.).

To verify protein expression in plants, $N$. benthamiana leaf samples (four $1-\mathrm{cm}^{2}$ disks) were collected 2 to 4 days after Agrobacterium spp. infiltration and frozen in liquid nitrogen. Proteins were extracted by grinding samples in $100 \mu \mathrm{l}$ of icecold PBS buffer supplemented with $6 \mathrm{M}$ urea, $0.1 \%$ Triton$\mathrm{X} 100,1 \mathrm{mM}$ phenylmethylsulfonyl fluoride, leupeptin at 1 $\mu \mathrm{g} / \mathrm{ml}$, and aprotinin at $1 \mu \mathrm{g} / \mathrm{ml}$. Samples were centrifuged and the supernatants were collected. Protein extracts were fractionated by SDS-PAGE and electroblotted onto nitrocellulose. Blots were probed and visualized as described above.

\section{ACKNOWLEDGMENTS}

We thank M. B. Mudgett for bacterial strains; M. Kupiec for fruitful discussions, yeast strains, and plasmids; A. Sharon for making his Zeiss Axioskop 2 microscope available; and members of the Sessa lab for critical comments on the manuscript. This work was supported by a research grant from the Israel Science Foundation (ISF; grant no. 326/10).

\section{LITERATURE CITED}

Abramovitch, R. B., Kim, Y. J., Chen, S., Dickman, M. B., and Martin, G. B. 2003. Pseudomonas type III effector AvrPtoB induces plant disease susceptibility by inhibition of host programmed cell death. EMBO (Eur. Mol. Biol. Organ.) J. 22:60-69.

Alfano, J. R., and Collmer, A. 2004. Type III secretion system effector proteins: Double agents in bacterial disease and plant defense. Annu. Rev. Phytopathol. 42:385-414.

Back, S. H., Schroder, M., Lee, K., Zhang, K., and Kaufman, R. J. 2005. ER stress signaling by regulated splicing: IRE1/HAC1/XBP1. Methods 35:395-416.

Barbet, N. C., Schneider, U., Helliwell, S. B., Stansfield, I., Tuite, M. F., and Hall, M. N. 1996. TOR controls translation initiation and early G1 progression in yeast. Mol. Biol. Cell 7:25-42.

Bartetzko, V., Sonnewald, S., Vogel, F., Hartner, K., Stadler, R., Hammes, U. Z., and Bornke, F. 2009. The Xanthomonas campestris pv. vesicatoria type III effector protein XopJ inhibits protein secretion: Evidence for interference with cell wall-associated defense responses. Mol. PlantMicrobe Interact. 22:655-664.

Block, A., Li, G., Fu, Z. Q., and Alfano, J. R. 2008. Phytopathogen type III effector weaponry and their plant targets. Curr. Opin. Plant Biol. 11:396-403.

Boch, J., and Bonas, U. 2010. Xanthomonas AvrBs3 family-Type III effec- tors: Discovery and function. Annu. Rev. Phytopathol. 48:419-436.

Buttner, D., and Bonas, U. 2006. Who comes first? How plant pathogenic bacteria orchestrate type III secretion. Curr. Opin. Microbiol. 9:193200.

Calderone, V., Forleo, C., Benvenuti, M., Thaller, M. C., Rossolini, G. M., and Mangani, S. 2006. A structure-based proposal for the catalytic mechanism of the bacterial acid phosphatase AphA belonging to the DDDD superfamily of phosphohydrolases. J. Mol. Biol. 355:708-721.

Campodonico, E. M., Chesnel, L., and Roy, C. R. 2005. A yeast genetic system for the identification and characterization of substrate proteins transferred into host cells by the Legionella pneumophila Dot/Icm system. Mol. Microbiol. 56:918-933.

Curak, J., Rohde, J., and Stagljar, I. 2009. Yeast as a tool to study bacterial effectors. Curr. Opin. Microbiol. 12:18-23.

Daniels, M. J., Barber, C. E., Turner, P. C., Cleary, W. G., and Sawczyc, M. K. 1984. Isolation of mutants of Xanthomonas campestris pv. campestris showing altered pathogenicity. J. Gen. Microbiol. 130:2447-2455.

Dudgeon, D. D., Zhang, N., Ositelu, O. O., Kim, H., and Cunningham, K W. 2008. Nonapoptotic death of Saccharomyces cerevisiae cells that is stimulated by Hsp90 and inhibited by calcineurin and $\mathrm{Cmk} 2$ in response to endoplasmic reticulum stresses. Eukaryot. Cell 7:2037-2051.

Espinosa, A., Guo, M., Tam, V. C., Fu, Z. Q., and Alfano, J. R. 2003. The Pseudomonas syringae type III-secreted protein HopPtoD2 possesses protein tyrosine phosphatase activity and suppresses programmed cell death in plants. Mol. Microbiol. 49:377-387.

Frederick, R. D., Thilmony, R. L., Sessa, G., and Martin, G. B. 1998. Recognition specificity for the bacterial avirulence protein AvrPto is determined by Thr-204 in the activation loop of the tomato Pto kinase. Mol. Cell 2:241-245.

Gerald, J. N., Benjamin, J. M., and Kron, S. J. 2002. Robust G1 checkpoint arrest in budding yeast: Dependence on DNA damage signaling and repair. J. Cell Sci. 115:1749-1757.

Gietz, D., St Jean, A., Woods, R. A., and Schiestl, R. H. 1992. Improved method for high efficiency transformation of intact yeast cells. Nucleic Acids Res. 20:1425.

Grant, S. R., Fisher, E. J., Chang, J. H., Mole, B. M., and Dangl, J. L. 2006. Subterfuge and manipulation: Type III effector proteins of phytopathogenic bacteria. Annu. Rev. Microbiol. 60:425-449.

Gurlebeck, D., Thieme, F., and Bonas, U. 2006. Type III effector proteins from the plant pathogen Xanthomonas and their role in the interaction with the host plant. J. Plant Physiol. 163:233-255.

Hotson, A., Chosed, R., Shu, H., Orth, K., and Mudgett, M. B. 2003. Xanthomonas type III effector XopD targets SUMO-conjugated proteins in planta. Mol. Microbiol. 50:377-389.

Huang, J., Lesser, C. F., and Lory, S. 2008. The essential role of the CopN protein in Chlamydia pneumoniae intracellular growth. Nature 456:112115.

Hutter, K. J., and Eipel, H. E. 1979. Microbial determinations by flow cytometry. J. Gen. Microbiol. 113:369-375.

Jamir, Y., Guo, M., Oh, H. S., Petnicki-Ocwieja, T., Chen, S., Tang, X. Dickman, M. B., Collmer, A., and Alfano, J. R. 2004. Identification of Pseudomonas syringae type III effectors that can suppress programmed cell death in plants and yeast. Plant J. 37:554-565.

Jones, J. B., Stall, R. E., and Bouzar, H. 1998. Diversity among Xanthomonads pathogenic on pepper and tomato. Annu. Rev. Phytopathol. 36:41-58.

Kaeberlein, M., and Guarente, L. 2002. Saccharomyces cerevisiae MPT5 and SSD1 function in parallel pathways to promote cell wall integrity. Genetics 160:83-95.

Kay, S., and Bonas, U. 2009. How Xanthomonas type III effectors manipulate the host plant. Curr. Opin. Microbiol. 12:37-43.

Kay, S., Hahn, S., Marois, E., Hause, G., and Bonas, U. 2007. A bacterial effector acts as a plant transcription factor and induces a cell size regulator. Science 318:648-651

Kim, J. G., Taylor, K. W., Hotson, A., Keegan, M., Schmelz, E. A., and Mudgett, M. B. 2008. XopD SUMO protease affects host transcription, promotes pathogen growth, and delays symptom development in Xanthomonas-infected tomato leaves. Plant Cell 20:1915-1929.

Kim, J. G., Li, X., Roden, J. A., Taylor, K. W., Aakre, C. D., Su, B., Lalonde, S., Kirik, A., Chen, Y., Baranage, G., McLane, H., Martin, G. B., and Mudgett, M. B. 2009. Xanthomonas T3S effector XopN suppresses PAMP-triggered immunity and interacts with a tomato atypical receptor-like kinase and TFT1. Plant Cell 21:1305-1323.

Kuo, S. C., and Lampen, J. O. 1974. Tunicamycin-an inhibitor of yeast glycoprotein synthesis. Biochem. Biophys. Res. Commun. 58:287-295.

Kuranda, K., Leberre, V., Sokol, S., Palamarczyk, G., and Francois, J. 2006. Investigating the caffeine effects in the yeast Saccharomyces cerevisiae brings new insights into the connection between TOR, PKC and Ras/cAMP signalling pathways. Mol. Microbiol. 61:1147-1166.

Lahiri, S. D., Zhang, G., Dunaway-Mariano, D., and Allen, K. N. 2006 
Diversification of function in the haloacid dehalogenase enzyme superfamily: The role of the cap domain in hydrolytic phosphorus carbon bond cleavage. Bioorg. Chem. 34:394-409.

Lopez-Solanilla, E., Bronstein, P. A., Schneider, A. R., and Collmer, A. 2004. HopPtoN is a Pseudomonas syringae Hrp (type III secretion system) cysteine protease effector that suppresses pathogen-induced necrosis associated with both compatible and incompatible plant interactions. Mol. Microbiol. 54:353-365.

Maayan, I., and Engelberg, D. 2009. The yeast MAPK Hog1 is not essential for immediate survival under osmostress. FEBS (Fed. Eur. Biochem. Soc.) Lett. 583:2015-2020.

Marchler-Bauer, A., Anderson, J. B., Chitsaz, F., Derbyshire, M. K., DeWeese-Scott, C., Fong, J. H., Geer, L. Y., Geer, R. C., Gonzales, N. R., Gwadz, M., He, S., Hurwitz, D. I., Jackson, J. D., Ke, Z., Lanczycki, C. J., Liebert, C. A., Liu, C., Lu, F., Lu, S., Marchler, G. H., Mullokandov, M., Song, J. S., Tasneem, A., Thanki, N., Yamashita, R. A., Zhang, D., Zhang, N., and Bryant, S. H. 2009. CDD: Specific functional annotation with the Conserved Domain Database. Nucleic Acids Res. 37:D205-210.

Martin, G. B., Bogdanove, A. J., and Sessa, G. 2003. Understanding the functions of plant disease resistance proteins. Annu. Rev. Plant Biol. 54:23-61.

Mendenhall, M. D., and Hodge, A. E. 1998. Regulation of Cdc28 cyclindependent protein kinase activity during the cell cycle of the yeast Saccharomyces cerevisiae. Microbiol. Mol. Biol. Rev. 62:1191-1243.

Metz, M., Dahlbeck, D., Morales, C. Q., Al Sady, B., Clark, E. T., and Staskawicz, B. J. 2005. The conserved Xanthomonas campestris pv. vesicatoria effector protein XopX is a virulence factor and suppresses host defense in Nicotiana benthamiana. Plant J. 41:801-814.

Munkvold, K. R., Martin, M. E., Bronstein, P. A., and Collmer, A. 2008. A survey of the Pseudomonas syringae pv. tomato DC3000 type III secretion system effector repertoire reveals several effectors that are deleterious when expressed in Saccharomyces cerevisiae. Mol. Plant-Microbe Interact. 21:490-502.

Munkvold, K. R., Russell, A. B., Kvitko, B. H., and Collmer, A. 2009. Pseudomonas syringae pv. tomato DC3000 type III effector HopAA1-1 functions redundantly with chlorosis-promoting factor PSPTO4723 to produce bacterial speck lesions in host tomato. Mol. Plant-Microbe Interact. 22:1341-1355

Nimchuk, Z. L., Fisher, E. J., Desveaux, D., Chang, J. H., and Dangl, J. L. 2007. The HopX (AvrPphE) family of Pseudomonas syringae type III effectors require a catalytic triad and a novel $\mathrm{N}$-terminal domain for function. Mol. Plant-Microbe Interact. 20:346-357.

Pedley, K. F., and Martin, G. B. 2003. Molecular basis of Pto-mediated resistance to bacterial speck disease in tomato. Annu. Rev. Phytopathol. 41:215-243.

Roden, J., Eardley, L., Hotson, A., Cao, Y., and Mudgett, M. B. 2004a. Characterization of the Xanthomonas AvrXv4 effector, a SUMO protease translocated into plant cells. Mol. Plant-Microbe Interact. 17:633-643.

Roden, J. A., Belt, B., Ross, J. B., Tachibana, T., Vargas, J., and Mudgett, M. B. 2004b. A genetic screen to isolate type III effectors translocated into pepper cells during Xanthomonas infection. Proc. Natl. Acad. Sci. U.S.A. 101:16624-16629.

Salomon, D., and Sessa, G. 2010. Identification of growth inhibition phe- notypes induced by expression of bacterial type III effectors in yeast. J. Vis. Exp. doi:10.3791/1865. Published online.

Sambrook, J., Fritsch, E. F., and Maniatis, T. 1989. Molecular Cloning: A Laboratory Manual, 2nd ed. Cold Spring Harbor Laboratory Press, Cold Spring Harbor, NY, U.S.A.

Schacherer, J., Ruderfer, D. M., Gresham, D., Dolinski, K., Botstein, D., and Kruglyak, L. 2007. Genome-wide analysis of nucleotide-level variation in commonly used Saccharomyces cerevisiae strains. PLoS One 2:e322. Published online.

Siggers, K. A., and Lesser, C. F. 2008. The yeast Saccharomyces cerevisiae: A versatile model system for the identification and characterization of bacterial virulence proteins. Cell Host Microbe 4:8-15.

Slagowski, N. L., Kramer, R. W., Morrison, M. F., LaBaer, J., and Lesser, C. F. 2008. A functional genomic yeast screen to identify pathogenic bacterial proteins. PLoS Pathog. 4:e9. Published online.

Thieme, F., Koebnik, R., Bekel, T., Berger, C., Boch, J., Buttner, D., Caldana, C., Gaigalat, L., Goesmann, A., Kay, S., Kirchner, O., Lanz, C., Linke, B., McHardy, A. C., Meyer, F., Mittenhuber, G., Nies, D. H., Niesbach-Klosgen, U., Patschkowski, T., Ruckert, C., Rupp, O., Schneiker, S., Schuster, S. C., Vorholter, F. J., Weber, E., Puhler, A., Bonas, U., Bartels, D., and Kaiser, O. 2005. Insights into genome plasticity and pathogenicity of the plant pathogenic bacterium Xanthomonas campestris pv. vesicatoria revealed by the complete genome sequence. J. Bacteriol. 187:7254-7266.

Thieme, F., Szczesny, R., Urban, A., Kirchner, O., Hause, G., and Bonas, U. 2007. New type III effectors from Xanthomonas campestris pv. vesicatoria trigger plant reactions dependent on a conserved N-myristoylation motif. Mol. Plant-Microbe Interact. 20:1250-1261.

Tokiwa, G., Tyers, M., Volpe, T., and Futcher, B. 1994. Inhibition of G1 cyclin activity by the Ras/cAMP pathway in yeast. Nature 371:342-345.

Valdivia, R. H. 2004. Modeling the function of bacterial virulence factors in Saccharomyces cerevisiae. Eukaryot. Cell 3:827-834.

White, F. F., Potnis, N., Jones, J. B., and Koebnik, R. 2009. The type III effectors of Xanthomonas. Mol. Plant Pathol. 10:749-766.

Wroblewski, T., Caldwell, K. S., Piskurewicz, U., Cavanaugh, K. A., Xu H., Kozik, A., Ochoa, O., McHale, L. K., Lahre, K., Jelenska, J., Castillo, J. A., Blumenthal, D., Vinatzer, B. A., Greenberg, J. T., and Michelmore, R. W. 2009. Comparative large-scale analysis of interactions between several crop species and the effector repertoires from multiple pathovars of Pseudomonas and Ralstonia. Plant Physiol. 150:1733-1749.

Yao, Q., Cui, J., Zhu, Y., Wang, G., Hu, L., Long, C., Cao, R., Liu, X., Huang, N., Chen, S., Liu, L., and Shao, F. 2009. A bacterial type III effector family uses the papain-like hydrolytic activity to arrest the host cell cycle. Proc. Natl. Acad. Sci. U.S.A. 106:3716-3721.

Yoon, S., Liu, Z., Eyobo, Y., and Orth, K. 2003. Yersinia effector YopJ inhibits yeast MAPK signaling pathways by an evolutionarily conserved mechanism. J. Biol. Chem. 278:2131-2135.

\section{AUTHOR-RECOMMENDED INTERNET RESOURCE}

RIKEN website: www.riken.go.jp 